\title{
An observed 20-year time series of Agulhas leakage
}

\author{
D. Le Bars ${ }^{1}$, J. V. Durgadoo ${ }^{2}$, H. A. Dijkstra ${ }^{1}$, A. Biastoch ${ }^{2}$, and W. P. M. De Ruijter ${ }^{1}$ \\ ${ }^{1}$ IMAU, Utrecht University, P.O. Box 80.005, 3508 TA Utrecht, The Netherlands \\ ${ }^{2}$ GEOMAR Helmholtz Centre for Ocean Research Kiel, Germany
}

Correspondence to: D. Le Bars (d.lebars@uu.nl)

Received: 2 December 2013 - Published in Ocean Sci. Discuss.: 15 January 2014

Revised: 9 May 2014 - Accepted: 12 May 2014 - Published: 3 July 2014

\begin{abstract}
We provide a time series of Agulhas leakage anomalies over the last 20-years from satellite altimetry. Until now, measuring the interannual variability of IndoAtlantic exchange has been the major barrier in the investigation of the dynamics and large scale impact of Agulhas leakage. We compute the difference of transport between the Agulhas Current and Agulhas Return Current, which allows us to deduce Agulhas leakage. The main difficulty is to separate the Agulhas Return Current from the southern limb of the subtropical "supergyre" south of Africa. For this purpose, an algorithm that uses absolute dynamic topography data is developed. The algorithm is applied to a state-of-the-art ocean model. The comparison with a Lagrangian method to measure the leakage allows us to validate the new method. An important result is that it is possible to measure Agulhas leakage in this model using the velocity field along a section that crosses both the Agulhas Current and the Agulhas Return Current. In the model a good correlation is found between measuring leakage using the full depth velocities and using only the surface geostrophic velocities. This allows us to extend the method to along-track absolute dynamic topography from satellites. It is shown that the accuracy of the mean dynamic topography does not allow us to determine the mean leakage but that leakage anomalies can be accurately computed.
\end{abstract}

\section{Introduction}

Agulhas leakage is the volume transport of Indian Ocean water that enters the South Atlantic south of Africa (Gordon, 1986). Because of its potential impact on the Atlantic Meridional Overturning Circulation (AMOC) (Weijer et al., 2002; Rühs et al., 2013) and hence global climate (Beal et al.,
2011), measuring and monitoring this quantity is highly relevant. Unfortunately, continuous measurements of the leakage have never been realized until now. The reason is that there is no method to do so. Contrary to the AMOC that can be measured across a fixed section, the whole Atlantic Basin, as done by the RAPID array (Srokosz et al., 2012), it is difficult to define a proper array to measure the Agulhas leakage. The ideal approach would be to measure continuously the total transport along, for example, the Good Hope section (Ansorge et al., 2005). It would then be necessary to differentiate the origin of the water and to isolate waters from the Indian Ocean. Because of large mixing in the Cape Basin (Boebel et al., 2003), using temperature and salinity to delineate the volume of leakage exported proves to be challenging, even in ocean models (van Sebille et al., 2010). It is also not possible to release specific passive tracers in the Indian Ocean and measure its concentration along the Good Hope section, as can be done in ocean models (Le Bars et al., 2012).

To solve this issue, Richardson (2007) measured leakage using a Lagrangian technique. Using the proportion of drifters and floats observed to have traveled from the Agulhas Current (AC) to the South Atlantic (9 out of 36) he approximated the leakage to be about $14.5 \mathrm{~Sv}$ with a "fairly large uncertainty". While this method provides an idea of the mean leakage, there are not enough floats and drifters released in the ocean to build a time series of the leakage. For comparison, it is necessary to release an order of magnitude of $10^{6}$ floats every year in ocean models to measure the leakage accurately (Doglioli et al., 2006; Biastoch et al., 2008; Van Sebille et al., 2009a).

Another technique developed by Souza et al. (2011) is to combine eddy detection with satellite altimetry and Argo floats to evaluate the volume transport of each Agulhas ring. 
This method is limited by the fact that these eddies quickly decay (Schouten et al., 2000), so it is difficult to evaluate precisely the amount of water that they remove from the AC. Also, considering anticyclonic eddies by definition ignores other forms of leakage. Cyclones could also carry some Indian Ocean water (Penven et al., 2001; Lutjeharms et al., 2003) and could filaments peel off the AC (Lutjeharms and Cooper, 1996). Also, water is advected through the Good Hope Jet (Bang and Andrews, 1974; Lutjeharms et al., 2007).

Given the observational challenge measuring leakage, several indicators were developed to measure it indirectly. Van Sebille et al. (2009b) found an anti-correlation between the AC transport and the Agulhas leakage in an ocean model, and proposed to use this relationship in the real ocean. Unfortunately, the dynamical relation between Agulhas Current and leakage was shown to be more complex than expected. In a similar model it is possible to increase the leakage through an increase of the westerlies that does not affect the AC (Durgadoo et al., 2013). It was also shown that, depending on the origin of the AC water (Indian Ocean or Pacific through the Indonesian Throughflow), the dynamics of the retroflection is different (Le Bars et al., 2013). Idealized models also show no reason to expect a linear relationship between AC and leakage (De Ruijter et al., 1999; Dijkstra and de Ruijter, 2001; Le Bars et al., 2012). Regardless of these results of the decorrelation between AC and leakage, it is not obvious that the $\mathrm{AC}$ transport could be measured accurately from an array of moorings. Because of the large local recirculation of water, it is difficult to differentiate the part of the water that is truly flowing south from that returning northward a few kilometers further offshore. Another indicator for the leakage is the position of the retroflection. It was used by Van Sebille et al. (2009a) to measure a time series of leakage from altimetry data with small variability and large uncertainty. This method has to assume a linear relationship between retroflection position and leakage and that this relation, as diagnosed in an ocean model, persists in the real ocean. It also neglects the possibility that the retroflection could be topographically "locked" (Matano, 1996; Franzese et al., 2009; Dencausse et al., 2010).

To avoid the difficult region of the Agulhas retroflection and the subsequent eddy formation region, the new method we propose here is based on measuring the leakage from the transport difference between the $\mathrm{AC}$ and the Agulhas Return Current (ARC). This simplified method is used because if we neglect the exchanges between the retroflection area and the South Atlantic Current extension then, in a steady state, the transport difference between the AC and the ARC should be exactly the Agulhas leakage. This includes anticyclonic eddies and all other forms of leakage. In the real ocean some lag will appear between AC, ARC and leakage in the South Atlantic. Therefore the signal that is observed along the satellite tracks should only be used for the evaluation of interannual variability of the leakage.
The transport is computed along several Topex/Poseidon satellite tracks. An algorithm is developed in Sect. 3 to locate the separation between the ARC and the southern limb of the subtropical "supergyre" (De Ruijter, 1982; Ridgway and Dunn, 2007) using either the absolute dynamic topography (ADT) from satellite or the sea surface height (SSH) from model data. The method is first validated in an ocean model in Sect. 4 before its application to altimetry data in Sect. 5 . A comparison between the model leakage and the altimetry derived leakage is presented in Sect. 6 and we conclude in Sect. 7.

\section{Data and model}

\subsection{Satellite altimetry}

We use satellite altimeter data produced by Ssalto/Duacs and distributed by AVISO (Archiving Validation and Interpretation of Satellite Data in Oceanography), with support from CNES $^{1}$ (National Centre for Space Studies). Two different data sets are used for this work. An along-track ADT that combines the Topex/Poseidon, Jason-1 and Jason-2 missions. Data were used between October 1992 and December 2012, with a time resolution of approximately 10 days and a horizontal resolution of $6 \mathrm{~km}$ in the region studied. Due to some missing data, we choose to decrease the time resolution from 10 days to 1 month. In this way each monthly ADT profile combines three or four cycles.

A mapped data set of ADT is also used over the same period. This is provided on a $1 / 3^{\circ} \times 1 / 3^{\circ}$ grid. The delayed time reference series was chosen as it provides a homogeneous data set based on two satellites (Jason-2/Envisat or Jason-1/Envisat or Topex/Poseidon/ERS) with a constant sampling in time. These two products of ADT make use of the MDT_CNES-CLS09 mean dynamic topography (MDT; Rio et al., 2011) that was produced by CLS (Collecte Localisation Satellites) Space Oceanography Division and distributed by AVISO, with support from CNES $^{2}$. This data set was averaged monthly to match the along-track data.

\subsection{Model}

In order to test our method, we employ the full 3-dimensional velocity as well as the SSH fields from the INALT01 model (Durgadoo et al., 2013). The INALT01 configuration is based on the NEMO (Nucleus for European Modelling of the Ocean v3.1.1; Madec (2008)) code, and is a high-resolution tenth-degree model of the greater Agulhas region, nested within a half-degree global ocean model. In the vertical, INALT01 has $46 z$ levels: 10 levels in the top $100 \mathrm{~m}$ and a maximum of $250 \mathrm{~m}$ resolution at depth. Bottom cells are partially filled. For the analysis, 60 years (1948-2007) of data

\footnotetext{
${ }^{1}$ see http://www.aviso.oceanobs.com/duacs/

2 see http://www.aviso.oceanobs.com/
} 

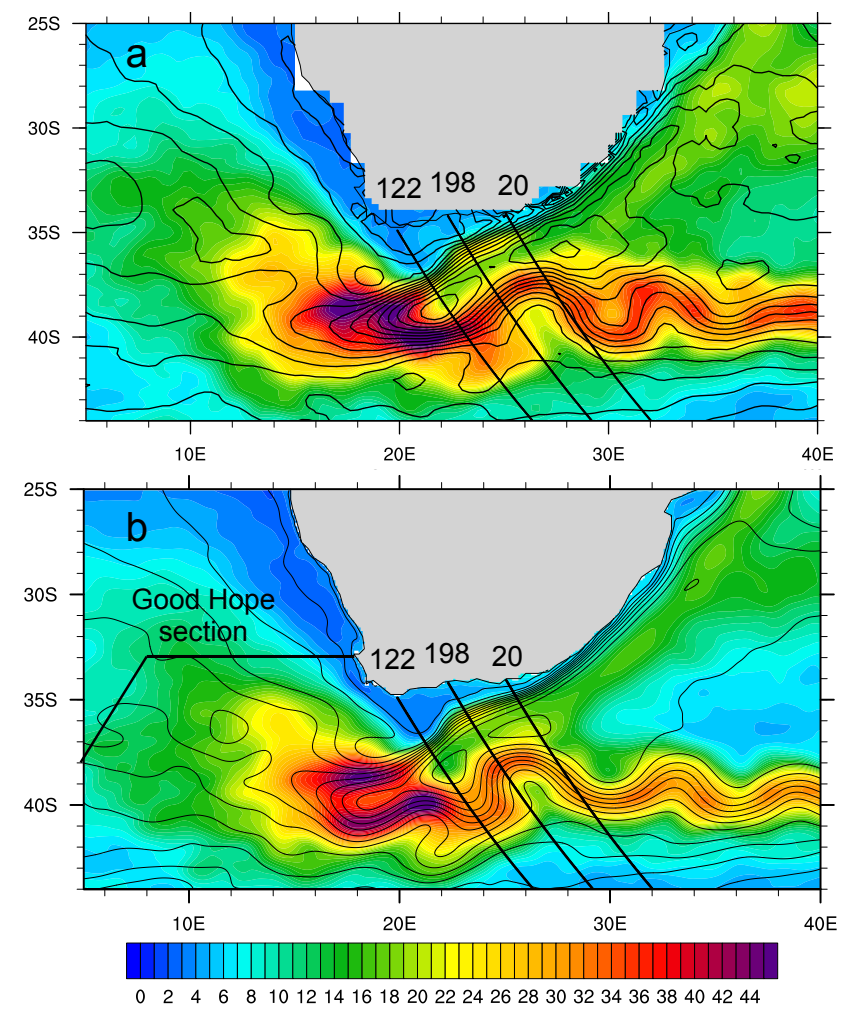

Figure 1. Mean values of absolute dynamic topography (contours) and its standard deviation (color, in $\mathrm{cm}^{2}$ ) with the Topex/Poseidon satellite tracks used for this work. (a) Mapped satellite altimetry product and (b) INALT01 model.

from a hindcast experiment are used. The forcing for the experiment is derived from the CORE2b data set (Large and Yeager, 2009).

The ARIANE Lagrangian package ${ }^{3}$ (Blanke et al., 1999) was used to measure Agulhas leakage within INALT01. Water parcels with an associated maximum transport of $0.1 \mathrm{~Sv}$ in 5 days $\left(4.32 \times 10^{10} \mathrm{~m}^{3}\right)$ were released along the satellite track 20 (see Fig. 1b) over the full depth. Parcels were released every 5 days over 1 year, and advected forward using the model's velocity fields for a total period of 5 years. Parcels reaching a section close to the Good Hope section (Ansorge et al., 2005) in the Cape Basin were captured and aggregated. These were defined as Agulhas leakage: the volume transport represented by the parcels flowing into the South Atlantic through the Good Hope section. Using this method, 56 annual values (1948-2003) of Agulhas leakage were obtained. The difference between this Lagrangian method and that of Durgadoo et al. (2013) is that the water parcels are released across a section following satellite track 20 instead of across the Agulhas Current at $32^{\circ} \mathrm{S}$. This approach leads to higher leakage values and is more appropriate for comparison with the new method presented in this paper.

\footnotetext{
${ }^{3}$ see http://www.univ-brest.fr/lpo/ariane
}

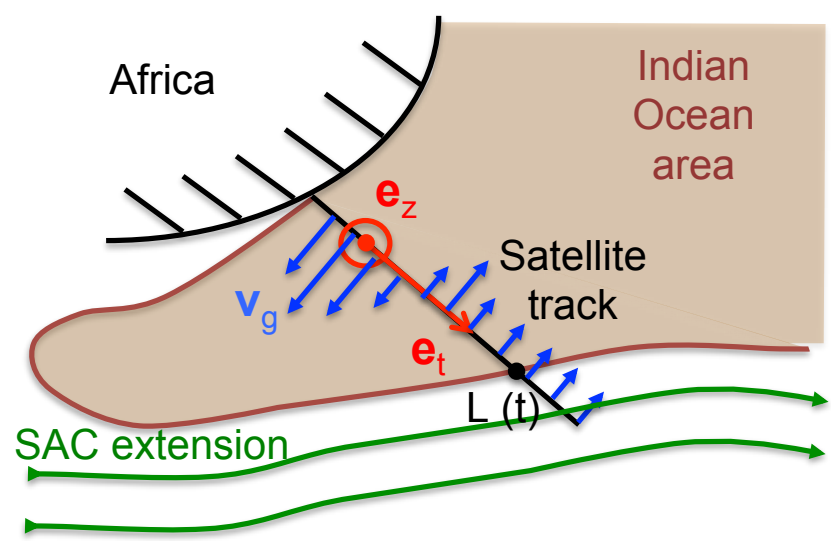

Figure 2. Schematic of vectors used for computation and variable $L$ separating the Indian Ocean area from the extension of the South Atlantic Current (SAC).

The INALT01 model is a new version of the AG01-R model that was used for many studies of the AC and Agulhas leakage (Biastoch et al., 2008, 2009; Van Sebille et al., 2009a; van Sebille et al., 2010). Comparison with satellite altimetry shows that it captures both the mean and the variability of the flow in the AC, Agulhas retroflection, and ARC (Fig. 1). One limitation of the model is the relatively weak recirculation cells between the AC and the ARC in the model compared to the altimetry. Using model SSH or satellite ADT we can compute geostrophic velocities normal to satellite tracks (see Fig. 2) as

$\boldsymbol{v}_{\mathrm{g}}=\frac{g}{f} \frac{\partial \eta}{\partial l} \boldsymbol{e}_{z} \times \boldsymbol{e}_{\mathrm{t}}$,

where $\boldsymbol{v}_{\mathrm{g}}$ is the geostrophic velocity perpendicular to the satellite track, $g$ is the gravitational acceleration, $f$ is the Coriolis parameter, $\eta$ is the absolute dynamic topography, $\boldsymbol{e}_{z}$ is a vertical unit vector, oriented upward, $\boldsymbol{e}_{\mathrm{t}}$ is a unit vector tangent to the satellite track, oriented offshore, and $l$ is a coordinate along $\boldsymbol{e}_{\mathrm{t}}$. The velocity $\boldsymbol{v}_{\mathrm{g}}$ is determined from Eq. (1) using central finite differences. The results show that the mean position and strength of the AC and ARC in the model compare well with the altimetry along the three chosen tracks (Fig. 3). This makes the model suitable to test our method to measure Agulhas leakage.

\section{Methodology}

The method computes the difference between AC and the ARC transports from altimetry along satellite tracks. In this way, we can measure leakage away from the energetic Agulhas retroflection. The three tracks we use are ideally located because they cross both the AC and the ARC almost perpendicularly (Fig. 1). They also have the advantage that firstly at these positions the AC core is not too close to the coast so the dynamic topography signal has a relatively good quality, 

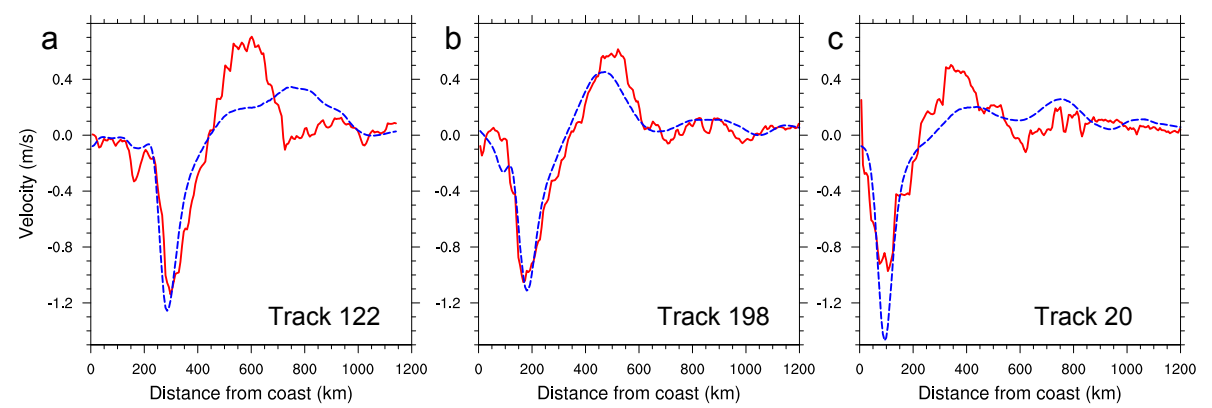

Figure 3. Along-track geostrophic velocities averaged over the period of time common to the model and satellite data (from October 1992 to December 2007) for model data (blue) and satellite data (red).

and secondly the ARC is limited in extension by the Agulhas Plateau. We define Agulhas leakage as the along-track cumulative transport from the coast to the distance $L$ and to the depth $H$ :

$\Phi_{\mathrm{A} L}(t)=\int_{0}^{L(t)} \int_{-H(l)}^{0} v(t, z, l) \mathrm{d} z \mathrm{~d} l$,

where $z$ is the vertical coordinate and $v$ is the velocity perpendicular to the track. Depending on the case we take $v$ either as the geostrophic velocity computed from the sea surface height field or the model velocity field. $H$ is the depth of integration, it is either the bottom topography or a maximum depth. As we want to integrate the full ARC, the point determining $L$ is located at the separation between the ARC and the southern limb of the subtropical "supergyre". The difference between these two currents is that the ARC originates from the AC. Therefore, we seek all the streamlines originating from the AC looping around to the ARC. If we assume geostrophic balance then the streamlines are contours of constant ADT. The following algorithm is used to detect these streamlines.

From a monthly mean field of ADT (Fig. 4a) the values of ADT higher than a certain threshold are selected (Fig. 4 b). The block of points connected to the Indian Ocean is then selected (Fig. 4c). Connected here means that all the grid cells in this group touch each other on at least one of their sides. This is performed using the Python function scipy.ndimage.measurements.label ${ }^{4}$. For instance, if an $\mathrm{Ag}$ ulhas ring detaches from the AC then its ADT value is high but it is not connected to the Indian Ocean anymore. Typically at the beginning of the algorithm, for high values of the threshold (high levels of ADT) the group of points represents only the heart of the southwestern Indian Ocean gyre. Then as the threshold is decreased, by increments of $1 \mathrm{~cm}$ the group of points becomes larger and larger. At some point there is a jump when the group of connected points extends

\footnotetext{
${ }^{4}$ see http://docs.scipy.org/doc/scipy/reference/generated/scipy. ndimage.measurements.label.html
}

all the way to the western Atlantic Ocean, as illustrated in Fig. 4d, which represents the group of Indian Ocean points for a threshold $1 \mathrm{~cm}$ lower than on panel $\mathrm{c}$. This happens because there is a region of relatively lower ADT values between the western Indian Ocean and the western Atlantic Ocean subtropical gyres. The patterns presented in Fig. 4c are selected because for an ADT threshold $1 \mathrm{~cm}$ smaller than the Indian Ocean group of points, represented by the red pattern, would extend west of $30^{\circ} \mathrm{W}$.

We define the optimal Indian Ocean group of points as the largest possible group with the condition that it should not extent "too far" in the Atlantic. Naturally the size of the group depends on what is defined as "too far". The sensitivity of the western end of the Indian Ocean group of points to the longitude of the western boundary used in the algorithm, e.g., the longitude for which we consider that the group extends "too far" in the Atlantic Ocean, is shown in Fig. 5. We see that for both the model and the altimetry data the western end of the Indian Ocean group of points converges towards a constant value for a western boundary longitude between 20 and $30^{\circ} \mathrm{W}$. The value at $30^{\circ} \mathrm{W}$ is therefore chosen for all the results in this paper as we see that the size of the Indian Ocean group of points has converged before this longitude for both the altimetry and the model. A simplified algorithm is presented.

\section{Algorithm:}

\section{Loop on time:}

Loop on ADT threshold (from high to low values, using increments of $1 \mathrm{~cm}$ ):

Select values of ADT higher than threshold.

Select group of points connected to the Indian Ocean.

If the group extends to $30^{\circ} \mathrm{W}$ :

Break the loop; the previous threshold is the ADT value that separates the ARC and the ACC.

Else: continue to loop.

The ADT threshold selected as described above represents the lowest ADT level that does not leak. This algorithm is applied on each monthly mean ADT field, and the threshold levels are used to compute the function $L$ at all times, $L$ being 

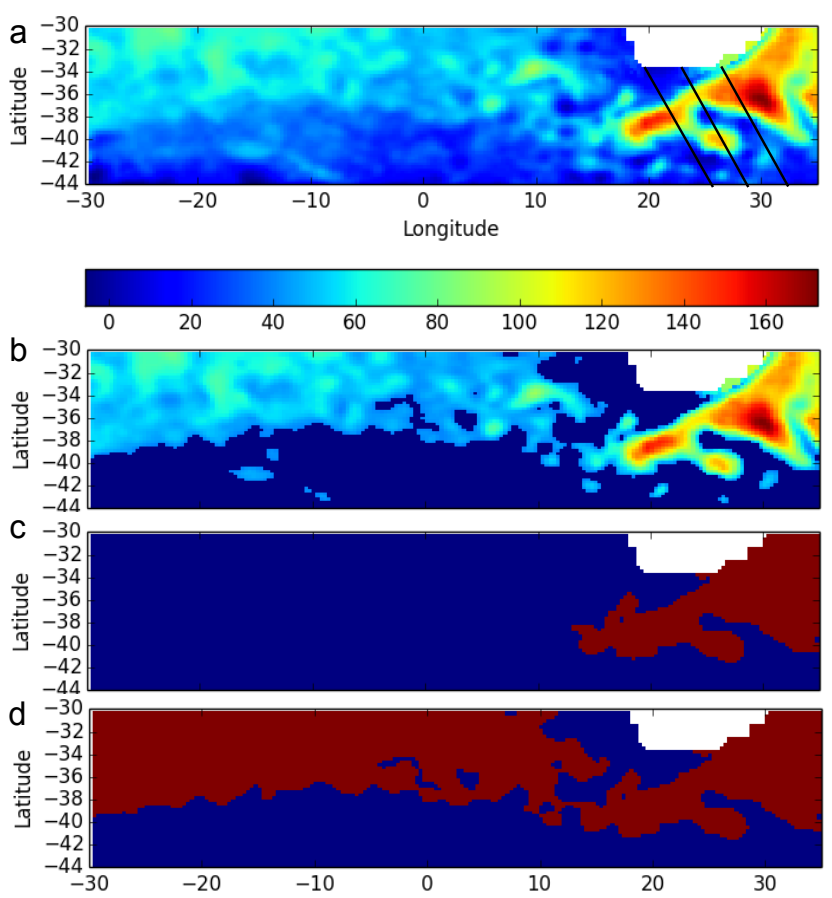

Figure 4. Selection of the limit between the ARC and the ACC using satellite ADT. (a) Initial ADT, (b) selection of the values of ADT higher than a certain threshold, (c) selection of the group of values corresponding to the Indian Ocean and (d) the extent of the Indian Ocean group for a threshold $1 \mathrm{~cm}$ smaller, showing a jump of the red area all the way to $30^{\circ} \mathrm{W}$.

the along-track distance from the coast to the location where the ADT crosses the threshold. Given the velocity along the track and the depth of integration, it is possible to compute the leakage along the satellite tracks. In the following sections this method is used for both model data and satellite altimetry.

\section{Measuring the leakage within INALT01}

Using the model we compare three methods to measure Agulhas leakage: (i) the traditional method of Lagrangian parcels, considered here as "ground truth", (ii) the integration of the full-depth model velocities along satellite tracks between the coast and the boundary of the ARC as determined by the algorithm presented in Sect. 3, and (iii) a reconstruction using only the model SSH.

\subsection{Using the full velocity field}

The vertical velocity profile within the model shows a surface intensified AC and ARC along the three satellite tracks (Fig. 6). To compute the leakage we choose to integrate the full-depth velocity. The parameter $H$ in Eq. (2) is the water column depth (for best comparison with the Lagrangian drifters method). Using Eq. (2) with the full-depth model

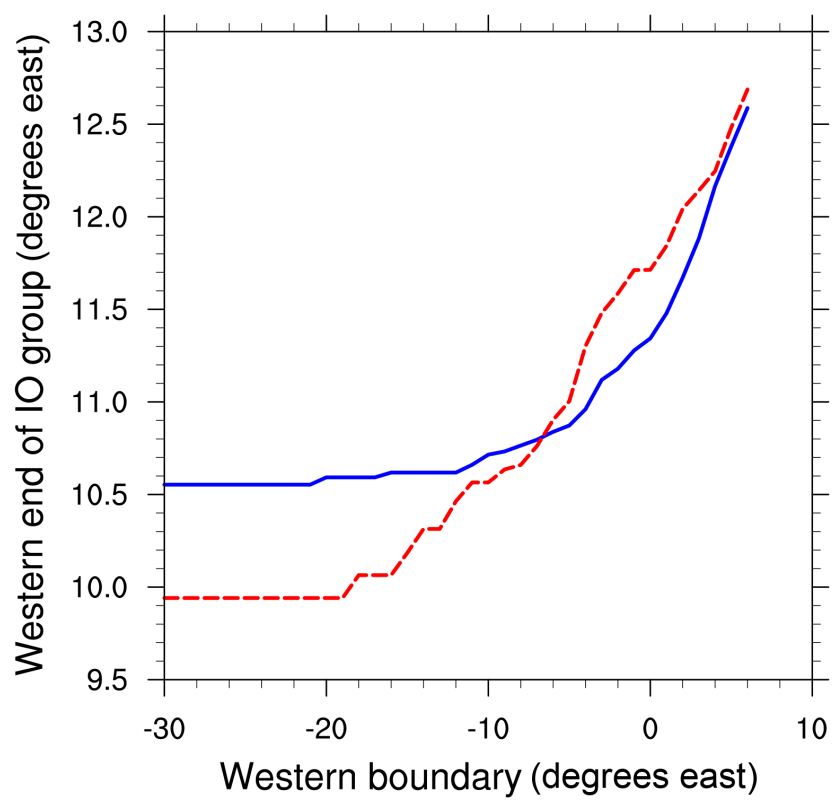

Figure 5. Convergence of the western limit of the group of Indian Ocean points with the position of the western boundary of the domain on which the algorithm is applied for model data (blue) and satellite data (red).

velocities we compute time series of leakage along the satellite tracks, and plot the annual averages (Fig. 7a). The results are similar along the three tracks, with a mean leakage of 19.8, 21.8 and $22.1 \mathrm{~Sv}$ along tracks 20,198 and 122 respectively. The standard deviation computed from monthly averages is high: $4.2,4.7$ and $6.7 \mathrm{~Sv}$ respectively, which leads to a low cross-correlation of the detrended time series: 0.41 between tracks 20 and 198 and 0.38 between tracks 198 and 122. Note that the time series all have a small positive trend. The cross-correlation is small mostly because of the deep ocean. If the top $1500 \mathrm{~m}$ is considered then the crosscorrelation between the transport along these tracks is 0.72 between tracks 20 and 198, and 0.81 between tracks 198 and 122. An explanation for the importance of the deep ocean in decorrelating the time series is that the signal could propagate slower at depth. It would then be necessary to take a lag between the different tracks to improve these correlations. This lag would have to depend on the depth and would probably have to be different for the AC and for the ARC, but this work is outside the scope of this paper.

Track 20 is chosen for comparison with the Lagrangian method because of the lower standard deviation of the leakage (see Fig. 7b). For the period 1948-2003, the mean leakage from the integration of the model velocity along track 20 is $19.4 \mathrm{~Sv}$ compared with $19.3 \mathrm{~Sv}$ from the Lagrangian method. These close numbers show that the algorithm that determines the separation between the ARC and the southern limb of the subtropical "supergyre" performs adequately. The time series of leakage computed with the two methods 


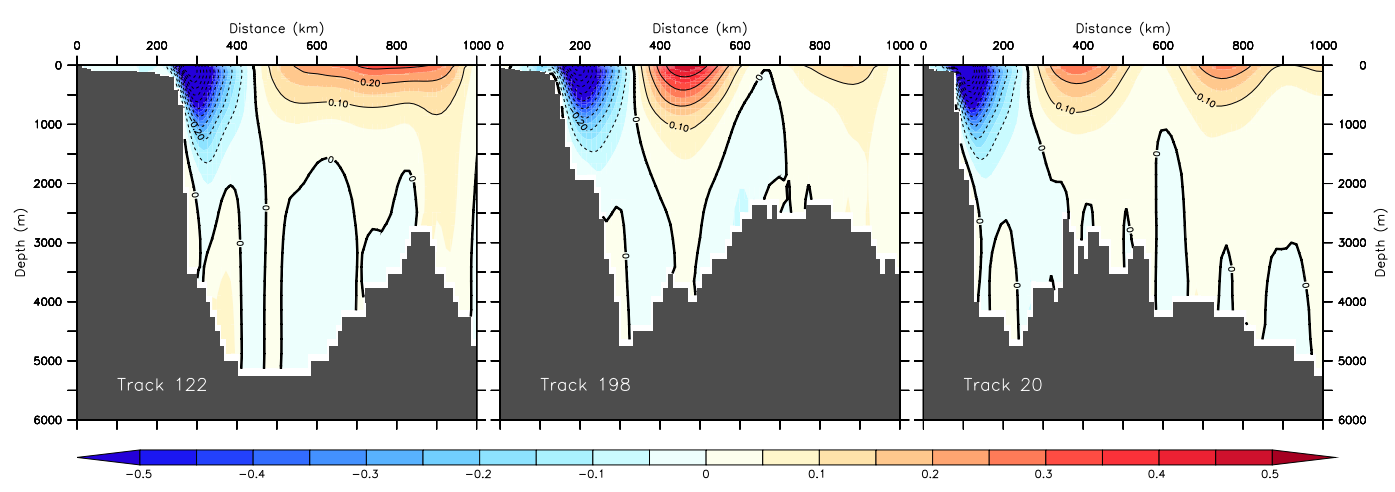

Figure 6. Depth profiles of the 60-year averaged velocity component normal to the satellite tracks in the INALT01. Positive values are in the northeast direction.

is also similar with a cross-correlation of 0.68 (Fig. 7b). A positive trend of 0.95 and $1.02 \mathrm{~Sv}$ per decade is found for the integration of model velocity and Lagrangian methods respectively.

These results demonstrate that it is possible to compute the leakage from the integration of the model velocities along the satellite tracks. We now compute the leakage from the SSH only.

\subsection{Using SSH}

In this section we aim to reproduce the leakage time series using only surface information. We compute geostrophic velocities from SSH according to Eq. (1), and integrate along each track, assuming that the velocities are constant until a certain depth, and zero below. The depth of the integration is chosen to have a mean leakage as close as possible to the computations using the model velocities. A maximum depth of $840 \mathrm{~m}$ gives a mean leakage of $19.4,19.4$ and $22.4 \mathrm{~Sv}$ along tracks 20,198 and 122 respectively, for the period 1958-2003 (Fig. 7c). The cross-correlations between the three leakage time series at different tracks using this method are higher than using the model velocity with 0.94 between tracks 20 and 198 and 0.91 between tracks 198 and 122. This is the result of a strong constraint on the volume transport due to the velocity integration between the coast and a value of SSH for each month. In fact, the transport of a barotropic geostrophic flow across a vertical section only depends on the depth of the section and on the difference of SSH at the beginning and at the end of this section (Wunsch and Stammer, 1998). The volume transport differs between the three tracks because the SSH is free to evolve at the coast, and because the depth, $H$, is not constant along the section, it follows the bottom topography until a depth of $840 \mathrm{~m}$.

More importantly, the leakage computed along track 20 from the SSH method compares well with the velocity integration method (Fig. 7b), with a cross-correlation of 0.78 . Obviously, if one is only interested in the surface flow then the cross-correlation increases. For instance, if the leakage

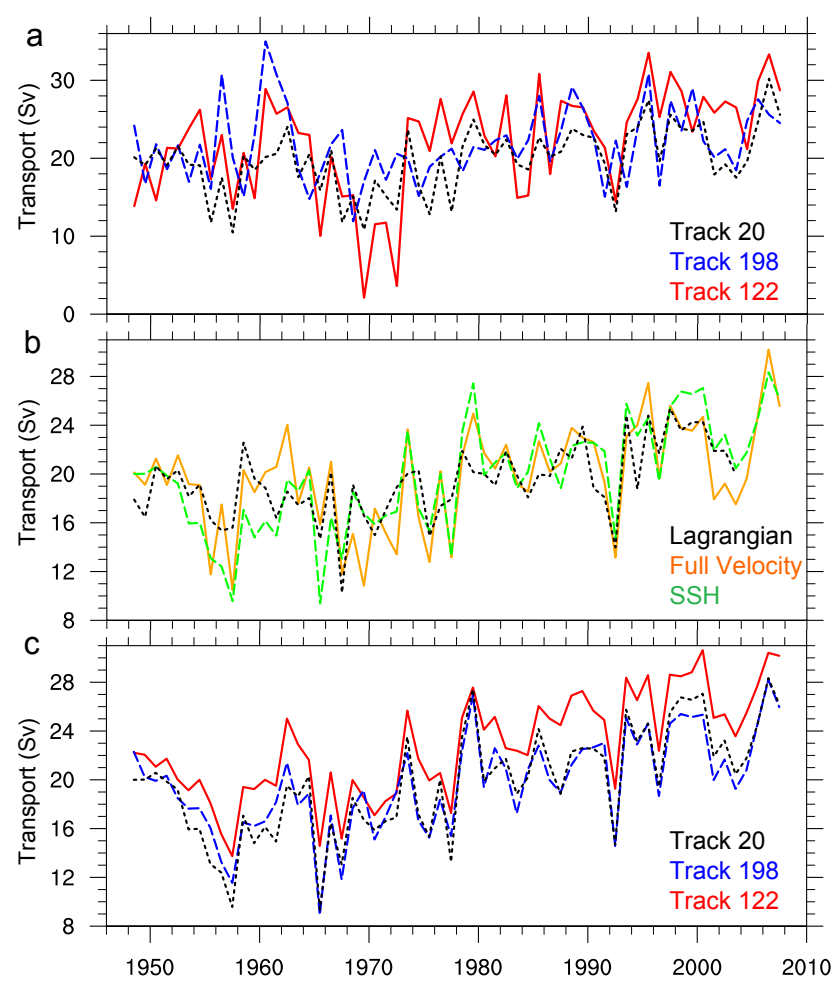

Figure 7. (a) Leakage computation from the integration of model velocity along three satellite tracks. (b) Comparison between three methods to compute the leakage over track 20 in the model: Lagrangian parcels (black), integration of full model velocity (orange) and derived from the SSH (green). (c) Leakage computation from the SSH method in the model. All the curves show annual averages.

is computed from Eq. (2) using model velocities from the surface to $1500 \mathrm{~m}$ depth then the cross-correlation with the $\mathrm{SSH}$ method is 0.86 . We also notice that for the other tracks the cross-correlation between the full depth transport and the method based on only SSH is smaller, it is 0.56 for track 122 and 0.16 along track 198. Along these tracks the transport is more baroclinic (see Fig. 6) and a more sophisticated method 


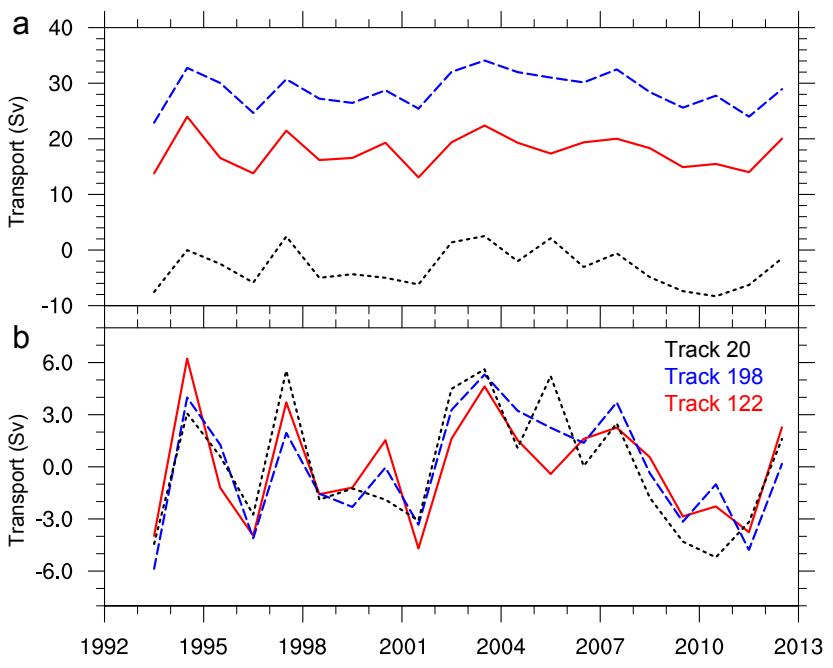

Figure 8. (a) Absolute value of leakage computation from satellite altimetry along three satellite tracks and (b) anomalies with respect to the time average.

of reconstruction of the deep flow either by computation of the normal modes (Gill, 1982; Wunsch, 1997) or by other eigenfunctions (Scott and Furnival, 2012) might prove useful. This is however outside the scope of this paper.

These results show that it is possible to have a good approximation of the leakage from "perfect measurements" of $\mathrm{SSH}$, as given by model outputs.

\section{Measuring the leakage from satellite altimetry}

It is possible to compute the leakage with the same method as presented in the previous section using satellite ADT. The surface geostrophic velocities are computed with Eq. (1) and the volume transport is integrated with Eq. (2) assuming that velocities are independent of the depth. Taking a maximum depth of $840 \mathrm{~m}$, which was shown to be appropriate for the model, three time series are constructed (Fig. 8a). Contrary to the time series computed from the model, Fig. 8a shows that the mean transport is different along the three tracks. This is likely due to the low accuracy of the mean dynamic topography. Errors of the order of $10 \mathrm{~cm}$ are expected (Rio et al., 2011) and such an error along a satellite track would lead to a difference of $9 \mathrm{~Sv}$ in the volume transport of leakage (Wunsch and Stammer, 1998). To avoid this important source of error we consider the anomalies with respect to the time average (Fig. 8b) and find a consistent signal from the three tracks. The cross-correlation between the leakage time series at tracks 20 and 198 is 0.86 and 0.88 between tracks 198 and 122. The difference between the three signals includes the measurement error and can be considered as the error of the method. Differences of up to $4 \mathrm{~Sv}$ can be found in 2005 and 2010, but the three signals agree on the overall interannual variability.

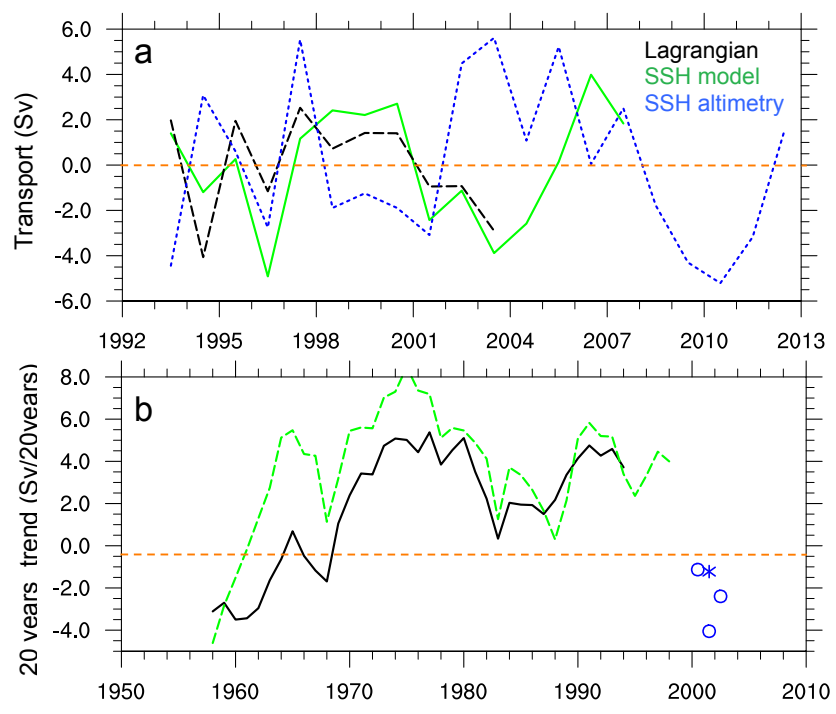

Figure 9. (a) Comparison of leakage anomaly computed from model output using the Lagrangian parcels (black) and the SSH method (green) and from satellite altimetry using the SSH method (blue) along track 20. (b) The 20-year trend ( $\mathrm{Sv}$ per 20 years) from the same methods as (a). The blue star is obtained from the 20 years of altimetry data and blue circles in are a sensitivity analysis of the trend computed over 18 years between 1993-2010, 1994-2011 and 1995-2012.

A direct comparison of the leakage anomaly within the model and altimetry computed with the same SSH method along track 20 shows a similar range of values, but no clear correlation (Fig. 9a). This is not a surprise because of the nonlinearity of the system and possible biases in the atmospheric forcing of the model. As the model simulation stops in 2007, only 15 years are available for comparison with the altimetry. Over this short period the trends have the same sign in the model and altimetry, 0.6 and $2.9 \mathrm{~Sv}_{\text {decade }}{ }^{-1}$ respectively. However, the trend of leakage computed over the 20 years of altimetry is close to zero or negative (Fig. 9b). This shows that, when computing trends of such short time series, a few years of additional data can have a big influence. If we compare with the model data, such a situation of a negative trend did not happen since the early 1960s. However, we have to be careful in the extrapolation of the results before the altimetry era, as we see that discrepancies are found between the model and the satellite data during the period where they overlap.

\section{Conclusions}

We presented a new method based on along-track and mapped satellite altimetry to measure the anomalies of the Agulhas leakage. This method is based on an algorithm that detects the separation between the ARC and the southern limb of the subtropical "supergyre", which allows us to 
measure the leakage by computing the transport difference between the $\mathrm{AC}$ and the $\mathrm{ARC}$. An important intermediate result is that we demonstrated it was possible to measure the leakage in an ocean model without the need to deploy numerical drifters as it is commonly done. This result allows us to make an accurate offline measure of the leakage with monthly output of the velocity fields instead of the higher frequency needed to advect numerical drifters. It could also be applied to ocean models of coarser horizontal resolution, like those used in climate models, which could facilitate studies of the climatic importance of the Agulhas leakage.

The main result is that an observed time series of Agulhas leakage has been generated using satellite ADT. Improvement of the method could be done by considering methods to reconstruct the deep velocities based on vertical dynamical modes (Gill, 1982). We also suggest that an array of moorings measuring vertical profiles of velocities along one of the satellite tracks presented in this paper could provide a very accurate time series of Agulhas leakage. For this, the array should cover both the AC and the ARC. The result would be a new time series comparable to the AMOC time series obtained from the RAPID array. Such a deployment of moorings, even if it is limited in time could lead to an improvement of the mean dynamic topography that could improve the measure of the mean leakage. The GOCE (Gravity field and Ocean Circulation Explorer) satellite and follow-up missions will also bring an improvement of the geoid height and mean dynamic topography. It is likely that this will make it possible to measure the mean leakage with more accuracy than the present result using the method described in this paper.

The time series of leakage anomaly obtained by the method suggests that the leakage has an important interannual variability, but there has been no substantial trend over the last 20 years. On these timescales this is not in line with the idea that in a warming climate the interocean exchange of water should increase due to a southward shift and strengthening of the westerlies (De Ruijter et al., 1999; Biastoch et al., 2009; Beal et al., 2011; Biastoch and Böning, 2013). Reasons could be that either delayed impacts on Agulhas leakage, such as as the adjustment of the Antarctic Circumpolar Current, come into play (Durgadoo et al., 2013), or that the strengthening trend of the westerlies is compensated by (natural) decadal climate variability. Indeed, observations of winds in the south Indian Ocean show no clear evidence for the expected changes over the last two decades (see Backeberg et al., 2012, Supplement). Model experiments with more recent forcing years and/or observational evidence for leakage changes over a longer time frame are necessary.

Acknowledgements. The authors would like to thank two anonymous referees and N. Swart for their useful comments on the manuscript. Dewi Le Bars, Wilhelmus P. M. De Ruijter and Henk A. Dijkstra are funded by the Netherlands Organization for Scientific Research through the INATEX program, ZKO no. 839.08.430. For the development of the model and its analysis funding was received from the European Community's Seventh Framework Programme FP7/2007-2013-Marie-Curie ITN, under grant agreement 238512, GATEWAYS project. Model experiments were performed at the High Performance Computing Centers in Stuttgart (HLRS). Jonathan V. Durgadoo and Arne Biastoch acknowledge funding by the Bundesministerium für Bildung und Forschung project SPACES 03G0835A.

Edited by: D. Stevens

\section{References}

Ansorge, I. J., Speich, S., Froneman, P. W., Rouault, M., and Garzoli, S.: Monitoring the oceanic flow between Africa and Antarctica: Report of the first GoodHope cruise, S. Afr. J. Sci., 101, 29-35, 2005.

Backeberg, B. C., Penven, P., and Rouault, M.: Impact of intensified Indian Ocean winds on mesoscale variability in the Agulhas system, Nature Climate Change, 2, 1-5, 2012.

Bang, N. D. and Andrews, W. R. H.: Direct current measurements of a shelf-edge frontal jet in the southern Benguela system, J. Marine Res., 32, 405-417, 1974.

Beal, L. M., De Ruijter, W. P. M., Biastoch, A., and Zahn, R.: On the role of the Agulhas system in ocean circulation and climate, Nature, 472, 429-436, 2011.

Biastoch, A. and Böning, C. W.: Anthropogenic impact on Agulhas leakage, Geophys. Res. Lett., 40, 1138-1143, 2013.

Biastoch, A., Lutjeharms, J. R. E., Böning, C. W., and Scheinert, M.: Mesoscale perturbations control inter-ocean exchange south of Africa, Geophys. Res. Lett., 35, 2000-2005, 2008.

Biastoch, A., Böning, C. W., Schwarzkopf, F. U., and Lutjeharms, J. R. E.: Increase in Agulhas leakage due to poleward shift of Southern Hemisphere westerlies, Nature, 462, 495-498, 2009.

Blanke, B., Arhan, M., Madec, G., and Roche, S.: Warm Water Paths in the Equatorial Atlantic as Diagnosed with a General Circulation Model, J. Phys. Oceanogr., 29, 2753-2768, 1999.

Boebel, O., Lutjeharms, J. R. E., Schmid, C., Zenk, W., Rossby, T., and Barron, C. N.: The Cape Cauldron: a regime of turbulent inter-ocean exchange, Deep Sea Res.-Pt. II, 50, 57-86, 2003.

De Ruijter, W. D.: Asymptotic analysis of the Agulhas and Brazil current systems, J. Phys. Oceanogr., 12, 1982.

De Ruijter, W. P. M., Biastoch, A., Drijfhout, S. S., Lutjeharms, J. R. E., Matano, R. P., Pichevin, T., Van Leeuwen, P. J., and Weijer, W.: Indian-Atlantic interocean exchange: Dynamics, estimation and impact, J. Geophys. Res., 104, 20885-20910, 1999.

Dencausse, G., Arhan, M., and Speich, S.: Spatio-temporal characteristics of the Agulhas Current retroflection, Deep Sea Res.-Pt. I, 57, 1392-1405, 2010.

Dijkstra, H. A. and de Ruijter, W. P. M.: On the physics of the Agulhas Current: Steady retroflection regimes, J. Phys. Oceanogr., 31, 2971-2985, 2001.

Doglioli, A. M., Veneziani, M., Blanke, B., Speich, S., and Griffa, A.: A Lagrangian analysis of the Indian-Atlantic interocean exchange in a regional model, Geophys. Res. Lett., 33, L14611, doi:10.1029/2006GL026498, 2006.

Durgadoo, J. V., Loveday, B. R., Reason, C. J. C., Penven, P., and Biastoch, A.: Agulhas Leakage Predominantly Responds to the 
Southern Hemisphere Westerlies, J. Phys. Oceanogr., 43, 21132131, 2013.

Franzese, A. M., Hemming, S. R., and Goldstein, S. L.: Use of strontium isotopes in detrital sediments to constrain the glacial position of the Agulhas Retroflection, Paleoceanography, 24, 112, 2009.

Gill, A. E.: Atmosphere-Ocean Dynamics, Vol. 30, Academic Press, San Diego, California, USA, 1982.

Gordon, A. L.: Interocean exchange of thermocline water, J. Geophys. Res., 91, 5037-5046, 1986.

Large, W. G. and Yeager, S. G.: The global climatology of an interannually varying air-sea flux data set, Clim. Dynam., 33, 341364, 2009.

Le Bars, D., De Ruijter, W. P. M., and Dijkstra, H. A.: A new regime of the Agulhas Current retroflection: turbulent choking of IndianAtlantic leakage, J. Phys. Oceanogr., 42, 1158-1172, 2012.

Le Bars, D., Dijkstra, H. A., and De Ruijter, W. P. M.: Impact of the Indonesian Throughflow on Agulhas leakage, Ocean Sci., 9, 773-785, doi:10.5194/os-9-773-2013, 2013.

Lutjeharms, J. and Cooper, J.: Interbasin leakage through Agulhas current filaments, Deep Sea Res.-Pt. I, 43, 213-238, 1996.

Lutjeharms, J. R. E., Boebel, O., and Rossby, H. T.: Agulhas cyclones, Deep Sea Res.-Pt. II, 50, 13-34, 2003.

Lutjeharms, J., Durgadoo, J., and Ansorge, I.: Surface drift at the western edge of the Agulhas Bank, 103, South African Journal of Science, 63-68, 2007.

Madec, G.: NEMO ocean engine, Note du Pole de modeisation de lílnstitut Pierre-Simon Laplace No. 27, Tech. rep., 2008.

Matano, R. P.: A numerical study of the Agulhas Retroflection: The role of bottom topography, J. Phys. Oceanogr., 26, 2267-2279, 1996.

Penven, P., Lutjeharms, J. R. E., Marchesiello, P., Roy, C., and Weeks, S. J.: Generation of cyclonic eddies by the Agulhas Current in the lee of the Agulhas Bank, Geophys. Res. Lett., 28, 1055-1058, 2001.

Richardson, P. L.: Agulhas leakage into the Atlantic estimated with subsurface floats and surface drifters, Deep Sea Res.-Pt. I, 54, 1361-1389, 2007.

Ridgway, K. R. and Dunn, J. R.: Observational evidence for a Southern Hemisphere oceanic supergyre, Geophys. Res. Lett., 34, L13612, doi:10.1029/2007GL030392, 2007.

Rio, M. H., Guinehut, S., and Larnicol, G.: New CNES-CLS09 global mean dynamic topography computed from the combination of GRACE data, altimetry, and in situ measurements, J. Geophys. Res., 116, C07018, doi:10.1029/2010JC006505, 2011.
Rühs, S., Durgadoo, J. V., Behrens, E., and Biastoch, A.: Advective timescales and pathways of Agulhas leakage, Geophys. Res. Lett., 40, 3997-4000, 2013.

Schouten, M. W., Ruijter, W. P. M. D., van Leeuwen, P. J., and Lutjeharms, J. R. E.: Translation, decay and splitting of Agulhas rings in the development, J. Geophys. Res, 105, 21913-21925, 2000.

Scott, R. B. and Furnival, D. G.: Assessment of Traditional and New Eigenfunction Bases Applied to Extrapolation of Surface Geostrophic Current Time Series to Below the Surface in an Idealized Primitive Equation Simulation, J. Phys. Oceanogr., 42, 165-178, 2012.

Souza, J. M. A. C., de Boyer Montègut, C., Cabanes, C., and Klein, P.: Estimation of the Agulhas ring impacts on meridional heat fluxes and transport using ARGO floats and satellite data, Geophys. Res. Lett., 38, L21602, doi:10.1029/2011GL049359, 2011.

Srokosz, M., Baringer, M., Bryden, H., Cunningham, S., Delworth, T., Lozier, S., Marotzke, J., and Sutton, R.: Past, Present, and Future Changes in the Atlantic Meridional Overturning Circulation, B. Am. Meteorol. Soc., 93, 1663-1676, 2012.

van Sebille, E., Barron, C. N., Biastoch, A., van Leeuwen, P. J., Vossepoel, F. C., and de Ruijter, W. P. M.: Relating Agulhas leakage to the Agulhas Current retroflection location, Ocean Sci., 5, 511-521, doi:10.5194/os-5-511-2009, 2009a.

van Sebille, E., Biastoch, A., Van Leeuwen, P. J., De Ruijter, W. P. M., Sebille, E. V., Leeuwen, P. J. V., and Ruijter, W. P. M. D.: A weaker Agulhas Current leads to more Agulhas leakage, Geophys. Res. Lett., 36, 10-13, 2009 b.

van Sebille, E., van Leeuwen, P. J., Biastoch, A., and de Ruijter, W. P.: Flux comparison of Eulerian and Lagrangian estimates of Agulhas leakage: A case study using a numerical model, Deep Sea Res.-Pt. I, 57, 319-327, 2010.

Weijer, W., De Ruijter, W. P. M., Sterl, A., and Drijfhout, S. S.: Response of the Atlantic overturning circulation to South Atlantic sources of buoyancy, Global Planet. Change, 34, 293-311, 2002.

Wunsch, C.: The vertical partition of oceanic horizontal kinetic energy, J. Phys. Oceanogr., 27, 1770-1794, 1997.

Wunsch, C. and Stammer, D.: Satellite altimetry, the marine geoid, and the oceanic general circulation, Annu. Rev. Earth Planet. Sc., 26, 219-253, 1998. 